\title{
Speciation of chromium in cow's milk by solid-phase extraction/dynamic reaction cell inductively coupled plasma mass spectrometry (DRC-ICP-MS) $\dagger$
}

\author{
Abayneh A. Ambushe, ${ }^{a}$ Robert I. McCrindle ${ }^{\star a}$ and Cheryl M. E. McCrindle ${ }^{b}$ \\ Received 7th November 2008, Accepted 22nd January 2009 \\ First published as an Advance Article on the web 17th February 2009 \\ DOI: $10.1039 / \mathrm{b819962k}$
}

Chromium can act either as an essential micronutrient or a chemical carcinogen, depending on its oxidation state. Of the two most stable chromium oxidation states, $\mathrm{Cr}(\mathrm{VI})$ is a known carcinogen, while $\mathrm{Cr}(\mathrm{III})$ is an essential element. Determination of total $\mathrm{Cr}$ cannot therefore be used to evaluate food safety of dairy products, as speciation is required for accurate assessment of potential toxicity. In this study, total $\mathrm{Cr}$ was determined by DRC-ICP-MS after mineralisation of freeze-dried milk samples. Chromabond $\mathrm{NH}_{2}$ ion-exchange columns were used to separate $\mathrm{Cr}(\mathrm{VI})$ from $\mathrm{Cr}(\mathrm{III})$. During the separation process, $\mathrm{Cr}(\mathrm{VI})$ was selectively adsorbed onto the Chromabond $\mathrm{NH}_{2}$ column. The retained $\mathrm{Cr}(\mathrm{VI})$ was subsequently eluted with two column volumes of $2 \mathrm{M} \mathrm{HNO}_{3}$ and diluted to a final volume of $10 \mathrm{~mL}$. After separation, the $\mathrm{Cr}(\mathrm{VI})$ was quantified by DRC-ICP-MS, using $\mathrm{O}_{2}$ as the reactive gas, to alleviate polyatomic ion interference. $\mathrm{An}_{2}$ gas flow rate of $0.85 \mathrm{ml} / \mathrm{min}$ and a high-pass rejection parameter $\mathrm{q}(\mathrm{Rpq})=0.5$, provided the best compromise signal-to-noise ratio. The method was validated through determining the recovery in milk samples spiked with $\mathrm{Cr}(\mathrm{VI})$. The recoveries were quantitative and ranged from 96.4 to $99.2 \%$. A whole milk powder reference material (NIST SRM 8435) was used to evaluate the accuracy of the total $\mathrm{Cr}$ quantification method. The observed value showed concordance with the certified value. The limits of detection (LOD) were 0.091 and $0.085 \mu \mathrm{g} / \mathrm{L}$ for total $\mathrm{Cr}$ and $\mathrm{Cr}(\mathrm{VI})$, respectively. These findings are important for the determination of maximum residue levels (MRLs) of $\mathrm{Cr}(\mathrm{VI})$ in dairy products.

\section{Introduction}

Chromium levels in the environment have gained special attention because of the serious health effects of the ionic forms of the metal discharged from industrial sources. In South Africa, environmental contamination by chromium results primarily from mining and smelting activities. ${ }^{1}$ Other sources include industrial processes such as electroplating, tanning, manufacture of pigments and chemicals, muds from oil drilling, textile dying, steel, paint and fertilizer production as well as wood preservation. ${ }^{2-4}$ During such industrial activities, chromium compounds are released as liquid, solid or gaseous wastes into the environment and can result in significant adverse biological and ecological effects. ${ }^{5}$

In natural environments, chromium mainly exists in two stable oxidation states: $\mathrm{Cr}$ (III) and $\mathrm{Cr}(\mathrm{VI})$. The two species are very different in charge and physicochemical properties as well as chemical and biochemical activity. $\mathrm{Cr}$ (III) is an essential trace element for both humans and animals, playing an important role in the normal glucose tolerance factor in insulin action and influencing carbohydrate, lipid and protein metabolism. ${ }^{6,7}$ In

${ }^{a}$ Tshwane University of Technology, Department of Chemistry, PO Box 56208, Arcadia,0007, South Africa.E-mail: mccrindleri@tut.ac.za; Fax: +27 12382 6286; Tel: +27 123826290

${ }^{b}$ University of Pretoria, Department of Paraclinical Sciences, Section Veterinary Public Health, Private Bag X04, Onderstepoort, 0110, South Africa

$\dagger$ This article is part of a themed issue dedicated to Professor Jean-Michel Mermet, in recognition of his contributions to the field of atomic spectrometry. contrast, $\mathrm{Cr}(\mathrm{VI})$ is carcinogenic and mutagenic, and has the capability of crossing cell membranes by way of non-specific anion carriers, causing skin ulcerations, nasal perforations and lung cancer. ${ }^{7,8}$

Humans are exposed when inhaling air, drinking water and eating food that may contain chromium. The average daily intake from air, water and food is estimated to be 0.01 to $0.03 \mu \mathrm{g}, 2 \mu \mathrm{g} / \mathrm{L}$, and $60 \mu \mathrm{g}$, respectively. ${ }^{9}$ The level of $\mathrm{Cr}(\mathrm{VI})$ sources is of particular interest in milk and dairy products, due to their nutritional importance. The role that milk plays in the nutrition of the newborn makes speciation of chromium important, as their rapid growth makes them more susceptible to its toxic effects.

Several previous studies have been conducted on the determination of total metal concentrations in milk, ${ }^{10-17}$ but in only a few cases, was speciation considered. Abollino et al. ${ }^{18}$ used solid-phase extraction (SPE) followed by inductively coupled plasma optical emission spectrometry (ICP-OES) for speciation of copper and manganese in milk. Cava-Montesinos et al. ${ }^{19}$ conducted speciation of arsenic and antimony in milk. These authors leached the elements using aqua regia. They then used direct determination, employing hydride generation atomic fluorescence spectrometry, both before and after reduction with potassium iodide. Speciation of iron in whey from breast milk and infant formulae, was carried out using high performance liquid chromatography (HPLC) and electrothermal atomic absorption spectrometry (ETAAS) ${ }^{20}$ Brätter et al. ${ }^{21}$ compared the protein-binding of trace elements in breast milk and infant formulae, by coupling HPLC with ICP-MS for the simultaneous speciation of trace elements, after separation of protein using size-exclusion chromatography (SEC). Lameiras et $a l^{22}$ 
quantified total $\mathrm{Cr}$ and $\mathrm{Cr}(\mathrm{VI})$ in UHT milk by ETAAS, after selective separation of $\mathrm{Cr}(\mathrm{VI})$ using a Chromabond $\mathrm{NH}_{2}$ column.

The quantification of trace levels of chromium species usually requires previous separation and/or pre-concentration stages, prior to detection by an instrumental technique. ${ }^{3}$ Various pre-concentration procedures such as complexation followed by solvent extraction, ${ }^{23}$ co-precipitation, ${ }^{24}$ supported liquid membrane ${ }^{1}$ and different chromatographic techniques ${ }^{25}$ were used for preconcentration and separation of chromium. SPE is also found to have a very important place in chromium speciation studies due to its simplicity, selectivity, flexibility, high enrichment factors, economic and environment friendliness, sampling in the field, safety, ease of automation and absence of emulsion formation. ${ }^{26}$

The objective of this study was to provide an alternative technique for speciation of chromium in cow's milk by DRCICP-MS after separation of $\mathrm{Cr}(\mathrm{VI})$ using a Chromabond $\mathrm{NH}_{2}$ ion-exchange column. In the present study, this SPE technique was adapted for pre-concentration and separation of $\mathrm{Cr}(\mathrm{VI})$ in cow's milk. Cr(VI) selectively adsorbed to the column was eluted with $\mathrm{HNO}_{3}$ and quantified by DRC-ICP-MS. Total $\mathrm{Cr}$ was determined by DRC-ICP-MS by applying the method developed in our laboratory. ${ }^{17}$ The ICP-MS has clear advantages in its speed of analysis, detection limits, and isotopic capabilities. However, accurate determination of elements such as chromium, using this technique, is usually hampered by polyatomic interferences. The problems of polyatomic interferences such as ${ }^{40} \mathrm{Ar}^{12} \mathrm{C}^{+}$, ${ }^{1} \mathrm{H}^{35} \mathrm{Cl}^{16} \mathrm{O}^{+},{ }^{40} \mathrm{Ar}^{13} \mathrm{C}^{+}$and ${ }^{37} \mathrm{Cl}^{16} \mathrm{O}^{+}$have been surmounted by employing DRC technology. ${ }^{23,27}$ The DRC technology allows an efficient removal of interferences by means of different chemical reactions occurring among analytes and interfering ions, using appropriate reaction gases. The reaction gases react with these interfering species before they enter the analyser. Charge transfer or even atom transfer reactions can be utilised because discrimination against unwanted reaction products is based on the band-pass setting of the DRC. The onset and width of the band-pass can be dynamically adjusted so that precursor ions with undesirable reaction products are rejected when a given analyte ion is being detected. The optimisation of the DRC-ICP-MS technique and its application to the determination of total $\mathrm{Cr}$ and $\mathrm{Cr}(\mathrm{VI})$ in selected milk samples are described in this paper.

Careful selection of the internal standard is necessary in order to overcome the presence of matrix interferences and instrumental drift. The internal standard should closely match the analyte element(s) in terms of mass number and ionization potential, so that possible interferences do not disturb the relationship between analyte and internal standard signals used for final determination. ${ }^{28}$

After validation of the developed method, the quantification of total $\mathrm{Cr}$ and $\mathrm{Cr}(\mathrm{VI})$ was conducted in eight different brands of pasteurised cow's milk purchased from supermarkets in Tshwane, South Africa.

\section{Experimental}

\section{Apparatus}

Chromabond $\mathrm{NH}_{2} / 3 \mathrm{~mL} / 500 \mathrm{mg}$ columns (i.e. aminopropyl phase with a $3 \mathrm{~mL}$ volume and $500 \mathrm{mg}$ of sorbent) were obtained from Macherey-Nagel (Düren, Germany). These columns were used to separate and concentrate $\operatorname{Cr}(\mathrm{VI})$ selectively, both in spikes and in the milk samples prior to quantification.

A HI 221 Microprocessor pH meter (Hanna Instruments, Padova, Italy) was used for monitoring $\mathrm{pH}$. The MEDIFRIGER centrifuge (J.P. SELECTA, Barcelona, Spain) was employed to separate protein from supernatant. An ultra-sonic bath (Ultrasons, J.P. SELECTA, Barcelona, Spain) was used for agitating the milk samples and the supernatant, before pouring it through the column. A model 13156 vacuum pump (Gelman Instruments Company, Fort Wayne, Indiana, USA) was used to dry the column under vacuum after adsorption of the sample.

A LP3 model freeze-dryer (Jouan, France) was used to dry liquid milk samples. The MARS 5 microwave digestion system (CEM Corporation, USA) was employed for mineralisation of freeze-dried milk samples. A Teflon XP-1500 Plus Vessel, allowing maximum decomposition pressure of 800 psi and temperature of $240^{\circ} \mathrm{C}$, was used for digestion. The High Pressure Digestion Vessel Accessory Sets (CEM Corporation, USA) permit simultaneous processing of up to $12 \mathrm{XP}-1500$ Plus vessels. At full power, the MARS delivers approximately $1200 \mathrm{~W}$ of microwave energy at a magnetron frequency of $2450 \mathrm{MHz}$. All glassware was washed with detergent and water. After being rinsed with de-ionised water $(18.2 \mathrm{M} \Omega \mathrm{cm})$ three times, it was soaked in $10 \% \mathrm{HNO}_{3}(\mathrm{v} / \mathrm{v})$ for $24 \mathrm{~h}$. This solution was discarded and the glassware was soaked again in $10 \% \mathrm{HNO}_{3}(\mathrm{v} / \mathrm{v})$ for $24 \mathrm{~h}$. The glassware was then rinsed three times with de-ionised water with a resistivity of $18.2 \mathrm{M} \Omega \mathrm{cm}$, and air-dried.

\section{Instrumentation}

ICP-MS measurements were performed by a quadrupole ELAN DRC-e spectrometer (PerkinElmer SCIEX, Concord, Ontario, Canada), equipped with a DRC. The sample delivery system

Table 1 Instrumental operating conditions of PerkinElmer ELAN DRC-e ICP-MS

\begin{tabular}{ll}
\hline Operating parameter & Setting \\
\hline Plasma power output & $1300 \mathrm{~W}$ \\
RF generator frequency & $40 \mathrm{MHz}$ \\
Analog stage voltage $($ volts) & -1850 \\
Pulse stage voltage (volts) & 1050 \\
Main water temperature $\left({ }^{\circ} \mathrm{C}\right)$ & 19 \\
Interface water temperature $\left({ }^{\circ} \mathrm{C}\right)$ & 31 \\
Torch box temperature $\left({ }^{\circ} \mathrm{C}\right)$ & 32 \\
Lens voltage $($ volts) & 7 \\
Argon flow rate $(\mathrm{L} / \mathrm{min})$ & Plasma: 15 , auxiliary: 1.2, \\
& nebuliser: $0.82-9.5$ \\
Analysis mode & DRC \\
DRC gas & $\mathrm{O}_{2}$ \\
DRC gas flow rate (ml/min) & 0.85 \\
DRC rejection parameter q (Rpq) & 0.5 \\
DRC rejection parameter a (Rpa) & 0 \\
Nebuliser type & Cross-flow \\
Spray Chamber type & Ryton $\AA$, double-pass \\
Interface & Pt sampler and skimmer cones, i.d. \\
& 1.1 and 0.9 mm, respectively \\
Torch & Standard quartz torch \\
Data acquisition & Peak hopping; dwell time per AMU \\
& 40 ms, sweeps/reading 60, \\
& number of replicates 3 \\
&
\end{tabular}


consisted of a PerkinElmer auto sampler model AS-93 Plus with as93f.try tray, peristaltic pump and a cross-flow nebuliser with a Scott type double pass spray chamber. The ICP and DRC conditions were selected to give the best compromise conditions. The same instrumental conditions were used for quantification of both total $\mathrm{Cr}$ and $\mathrm{Cr}(\mathrm{VI})$. Details on the instrumentation and the operating conditions are summarised in Table 1.

\section{Reagents}

All solutions were prepared using ultra pure reagents. The water used in this work was doubly de-ionised with the final stage of de-ionisation provided by a Milli-Q water purification system (Millipore, Bedford, MA, USA). High purity $\mathrm{HNO}_{3}(65 \%$, Suprapur, Merck, Darmstadt, Germany) was used for cleaning glassware, digesting milk samples, column conditioning and elution of $\mathrm{Cr}(\mathrm{VI})$. Sodium acetate (Merck, Darmstadt, Germany) and acetic acid glacial (Merck Chemicals (PTY) LTD, Gauteng, South Africa) were used for buffer preparation and $\mathrm{pH}$ adjustment. Alizarin (BDH chemicals Ltd, Poole, England) was used for binding $\mathrm{Cr}$ (III) to prevent oxidation. A stock standard solution containing $1000 \mathrm{mg} / \mathrm{L}$ of total $\mathrm{Cr}$ and $\mathrm{Cr}(\mathrm{VI})$ (TEKNOLAB A/S, Kolbotn, Norway) was used in preparing calibration standards. The calibration solutions were prepared from the stock solution using de-ionised water $(18.2 \mathrm{M} \Omega \mathrm{cm})$ immediately before analysis. An internal standard solution containing $10 \mathrm{mg} / \mathrm{L}$ of $\mathrm{Ga}$, was prepared from a single-element standard solution (1000 mg/L) (TEKNOLAB A/S, Kolbotn, Norway). The mass calibration stock solution containing $\mathrm{Ba}, \mathrm{Be}$, $\mathrm{Ce}, \mathrm{Co}, \mathrm{In}, \mathrm{Mg}, \mathrm{Pb}, \mathrm{Rh}$ and $\mathrm{U}$, at $10 \mu \mathrm{g}$ element/L was obtained from PerkinElmer (Concord, Ontario, Canada). $\mathrm{CHCl}_{3}$ (Sigma Aldrich, South Africa) was used in preparing a $0.1 \% \mathrm{CHCl}_{3}$ in $2 \% \mathrm{HNO}_{3}$ blank solution (simulated matrix), that was introduced into the nebulisation system for optimisation of DRC conditions. Instrument grade argon, oxygen and methane gases (Afrox, South Africa) were used for DRC-ICP-MS.

A whole milk powder reference material (NIST SRM 8435 , Gaithersburg, MD, USA) was employed to check the accuracy and precision of the final quantification of total $\mathrm{Cr}$ in milk samples.

\section{Standards}

Standard solutions were prepared daily by appropriate dilution of stock standard $1000 \mathrm{mg} / \mathrm{L}$ of total $\mathrm{Cr}$ and $\mathrm{Cr}(\mathrm{VI})$ (TEKNOLAB A/S, Kolbotn, Norway). Quantification of total $\mathrm{Cr}$ and $\mathrm{Cr}(\mathrm{VI})$ concentrations were performed, establishing calibration curves with external standards prepared in $1 \% \mathrm{v} / \mathrm{v}$ ultrapure $\mathrm{HNO}_{3}$ for analysis of all samples. The calibration curve was made from 5 points and the blank.

\section{Samples}

One litre bottles $(n=8)$ of pasteurised cow's milk of eight different commercial brands, were purchased from the major supermarkets in Tshwane, South Africa. Different brands of pasteurised milk were selected because each distributor has its own group of producers and there is no overlapping. Three 40 $\mathrm{mL}$ samples were taken from each bottle to validate repeatability and precision of the method used to quantify total $\mathrm{Cr}$ and $\mathrm{Cr}(\mathrm{VI})$. The number of samples evaluated thus totalled 24 .

\section{Sample preparation}

Sample preparation for determination of $\mathrm{Cr}(\mathrm{VI})$. Pre-concentration and separation of $\mathrm{Cr}(\mathrm{VI})$ was performed according to the procedure described the in literature, ${ }^{22}$ with slight modifications. Each $40 \mathrm{~mL}$ of milk was mixed with $5 \mathrm{~mL}$ of buffer ( $\mathrm{pH} 3.5)$. The samples were sonicated for $10 \mathrm{~min}$ in an ultrasonic bath. They were then centrifuged at $3000 \mathrm{rpm}$ at a temperature of $4{ }^{\circ} \mathrm{C}$ for 30 min. The supernatant was transferred to another flask. Then $0.001 \%$ alizarin $(5 \mathrm{~mL})$ was added and the mixture was agitated for $2 \mathrm{~min}$. Thereafter, $40 \%$ sodium acetate was added until a $\mathrm{pH}$ of 4.9 was obtained. This solution was homgenised and poured through the previously conditioned column. The columns were first conditioned with two column volumes of $1 \mathrm{M} \mathrm{HNO}_{3}$, then with two column volumes of de-ionised water, before sample loading.

Selective retention of $\mathrm{Cr}(\mathrm{VI})$ in the column was quantitatively achieved by passing the supernatant through the column under vacuum. After adsorption of the sample, the column contents were dried under vacuum and $\mathrm{Cr}(\mathrm{VI})$ was eluted with two column volumes of $2 \mathrm{M} \mathrm{HNO}_{3}$. The final volumes of sample solutions were adjusted to $10 \mathrm{~mL}$ with de-ionised water.

Sample preparation for determination of total Cr. Samples for quantification of total $\mathrm{Cr}$ were prepared by applying the method reported previously. ${ }^{17}$ A $0.5 \mathrm{~g}( \pm 0.0001)$ aliquot of freeze-dried and crushed milk sample was accurately weighed and quantitatively transferred to each XP-1500Plus vessel. The sample was reconstituted with $2 \mathrm{ml}$ of $18.2 \mathrm{M} \Omega \mathrm{cm}$ de-ionised water. Then 4 $\mathrm{ml}$ of $65 \% \mathrm{HNO}_{3}$ (Suprapur, Merck, Darmstadt, Germany) was added to each sample and the vessels were allowed to stand open until the initial reaction subsided. The samples were mineralised in the MARS 5 microwave digestion system (CEM Corporation, USA), employing the following programme: pressure control, 10 min ramp, $20 \mathrm{~min}$ hold, maximum pressure 500 psi and maximum temperature $200{ }^{\circ} \mathrm{C}$. A blank solution was prepared by digesting $2 \mathrm{ml}$ of $18.2 \mathrm{M} \Omega \mathrm{cm}$ de-ionised water and $4 \mathrm{ml}$ of $65 \%$ $\mathrm{HNO}_{3}$ (Suprapur, Merck, Darmstadt, Germany), using the same digestion procedure. The digested samples and reagent blank were diluted to $25 \mathrm{ml}$. All digestions were prepared in triplicate.

All vessels were automatically cooled for 20 minutes following the completion of the digestion program. The pressure was vented and vessel covers were removed. After mineralisation, the samples were quantitatively transferred to $25 \mathrm{ml}$ volumetric flasks and brought up to the mark with ultra pure de-ionised water. Blanks, consisting of de-ionised water and reagents were subjected to a similar sample preparation and analytical procedure.

Sample analysis. Total $\mathrm{Cr}$ and $\mathrm{Cr}(\mathrm{VI})$ concentrations in milk samples were estimated using the ELAN DRC-e ICP-MS instrument equipped with a cross flow nebuliser, platinum cones and a peristaltic sample delivery tube. Before each measurement series, the instrument had undergone a 45-60 min routine conditioning and optimisation procedure. The operating conditions for ICP-MS measurements were optimised daily, by 
monitoring signals produced by a multi-elemental solution containing $10 \mu \mathrm{g} / \mathrm{L} \mathrm{Ba}, \mathrm{Be}, \mathrm{Ce}, \mathrm{Co}, \mathrm{In}, \mathrm{Mg}, \mathrm{Pb}, \mathrm{Rh}$ and $\mathrm{U}$ in the Graphics mode of analysis. The selected conditions were those, which maximize ${ }^{115} \mathrm{In}$ and equal signals for ${ }^{24} \mathrm{Mg}$ and ${ }^{208} \mathrm{~Pb}$.

The DRC conditions were optimised independently from the remainder of the ICP-MS system. The cell gas flow rate and the high-pass rejection parameter $\mathrm{q}(\mathrm{Rpq})$ value, were optimised to achieve the highest signal to noise ratio. The low-pass rejection parameter a (Rpa), was set at 0 . Two solutions were used for the DRC optimisation. The blank contained possible interfering species of chromium and was composed of $0.1 \% \mathrm{CHCl}_{3}$ in $2 \%$ $\mathrm{HNO}_{3}$. The standard solution contained the interfering matrix (blank solution) together with a $10 \mu \mathrm{g} / \mathrm{L} \mathrm{Cr}$ spike. Optimisation of the cell gas flow rate and $\mathrm{Rpq}$ value were conducted using these solutions. DRC conditions were selected to minimize the interference of polyatomic ions, also to retain a better sensitivity for analyte.

$\mathrm{Cr}$ has four stable isotopes ${ }^{50} \mathrm{Cr}(4.35 \%), \quad{ }^{52} \mathrm{Cr}(83.8 \%)$, ${ }^{53} \mathrm{Cr}(9.50 \%)$, and ${ }^{54} \mathrm{Cr}(2.37 \%)$. The most abundant isotopes, which showed less interferences from the matrix $\left({ }^{52} \mathrm{Cr}\right.$ and $\left.{ }^{53} \mathrm{Cr}\right)$, were selected for simultaneous monitoring. Software (ELAN version 3.0, PerkinElmer SCIEX, Canada) was programmed to apply the corresponding correction equations.

Concentrations of total $\mathrm{Cr}$ and $\mathrm{Cr}(\mathrm{VI})$ in milk samples were determined using external calibration. Blank, standard and milk sample solutions were nebulised. Each solution (of either standard or sample) was followed by introduction of de-ionised water, for at least $1 \mathrm{~min}$, to rinse the sampling system, in order to avoid contamination by previous solutions. Three independent replicates of each sample were measured, and the concentrations were calculated using the average of each value. The blank samples were also measured. The intensity of each analyte in the blank sample was subtracted from that of the sample.

Selection of internal standard. In this study, ${ }^{69} \mathrm{Ga}$ was used as internal standard. The extracted samples, digested milk samples, blanks and calibration standards were spiked with ${ }^{69} \mathrm{Ga}$ internal standard solution, to obtain a final concentration of $10 \mu \mathrm{g} / \mathrm{L}$. Using ${ }^{69} \mathrm{Ga}$ internal standards allowed accurate and precise quantification of $\mathrm{Cr}(\mathrm{VI})$ in spiked milk samples and total $\mathrm{Cr}$ in the reference material (SRM 8435). Thus, external calibration with ${ }^{69} \mathrm{Ga}$ as internal standard was employed for final quantification of $\mathrm{Cr}(\mathrm{VI})$ and total $\mathrm{Cr}$ in milk samples.

Determination of limits of detection (LOD). To determine the LOD of the whole analytical procedure, reagent blanks were prepared following the same procedures for the quantification of total $\mathrm{Cr}$ and $\mathrm{Cr}(\mathrm{VI})$ in milk. The intensities of 10 blanks were measured. Standard deviations were calculated from the intensity readings of these 10 blanks. The LODs for the species under study, based on three times the standard deviation $(3 \sigma)$ of the average of 10 individually prepared blank solutions were calculated.

Quality assurance/Quality control performance. For the assessment of the accuracy of the concentration of $\mathrm{Cr}(\mathrm{VI})$ quantified, a recovery study was conducted by spiking milk samples with $2.50,5.00$, and $10.0 \mu \mathrm{g} / \mathrm{L}$ of $\mathrm{Cr}(\mathrm{VI})$. The stability of $\mathrm{Cr}(\mathrm{VI})$ in milk was also evaluated by adding $10.0 \mu \mathrm{g} / \mathrm{L}$ of $\mathrm{Cr}(\mathrm{VI})$ standard solution. After standing for 12, 24 and $48 \mathrm{~h}$ the spiked samples were analysed as described above and $\mathrm{Cr}(\mathrm{VI})$ quantified. The accuracy of the total $\mathrm{Cr}$ quantification method was evaluated using a whole milk powder reference material (NIST SRM 8435, Gaithersburg, MD, USA).

\section{Results and discussion}

\section{Selection of DRC-ICP-MS conditions}

Interferences due to ions having the same mass as the analyte can be a major problem in a quadrupole ICP-MS that restricts the resolution to one mass unit. Therefore, ions with the same nominal mass as the analyte (single, doubly charged and polyatomic ions) cannot be resolved. These interferences originate from chemical species present in the Ar plasma, atmospheric gases, reagents and sample matrix. In particular, the determination of elements between 40 and 82 amu caused problems due to the presence of these polyatomic interferences. ${ }^{29}$ In order to conduct accurate quantification, mass interferences should be identified, corrected, or if possible, eliminated.

Chromium is recognised as an element that is subject to interference by polyatomic ions formed in the plasma. The most common of these is ${ }^{40} \mathrm{Ar}^{12} \mathrm{C}+$ at $m / z=52$ but others may include chlorine based interferences such as ${ }^{1} \mathrm{H}^{35} \mathrm{Cl}^{16} \mathrm{O}^{+}(\mathrm{m} / \mathrm{z} 52),{ }^{37} \mathrm{Cl}^{15} \mathrm{O}$ ( $m / z 52)$, and ${ }^{37} \mathrm{Cl}^{16} \mathrm{O}+(m / z 53)$, which have the same $m / z$ as ${ }^{52} \mathrm{Cr}^{+}$ and ${ }^{53} \mathrm{Cr}^{+}$, respectively.

According to the literature, different collision and reaction gases have been used to react specifically or more rapidly with interfering polyatomic ions. During the determination of trace elements, including chromium in foodstuffs of animal origin, satisfactory results were reported using $\mathrm{H}_{2}$ and $\mathrm{He}$ gases in collision cell technology (CCT) mode. ${ }^{30}$ Other studies employing CCT systems demonstrated the effectiveness of $\mathrm{H}_{2}$ and $\mathrm{He}$ gases, in terms of reduction of the argon-based interferences and limits of detection. ${ }^{31,32}$ Reactive gases such as $\mathrm{NH}_{3}$ and $\mathrm{CH}_{4}$ were tested on DRC mode, for quantification of chromium in food, biological fluids and environmental samples. ${ }^{23,27,33-36}$ The reaction gas $\mathrm{NH}_{3}$, was found to be more efficient than $\mathrm{CH}_{4} \cdot{ }^{35}$ Because of the incompatibility between our ICP-MS system and the corrosive reaction gas $\left(\mathrm{NH}_{3}\right), \mathrm{CH}_{4}$ and $\mathrm{O}_{2}$ reaction gases were tested in this study.

The effect of the operating conditions of DRC for alleviating background signals at different chromium masses $\left({ }^{52} \mathrm{Cr}\right.$ and $\left.{ }^{53} \mathrm{Cr}\right)$ was studied. Several parameters affected the operation of the DRC. The type and flow rate of the reaction gas and values of the rejection parameter $\mathrm{q}(\mathrm{Rpq})$ and rejection parameter a (Rpa), of the DRC system were assessed. Investigations were also conducted on varying $\mathrm{CH}_{4}$ and $\mathrm{O}_{2}$ flow rates as well as the $\mathrm{Rpq}$ values, to obtain reliable DRC operating parameters that provided the best compromise for signal-to-noise ratio $(\mathrm{S} / \mathrm{N})$. Selection of the best flow rate of reaction gas and optimisation of the high-pass rejection parameter ( $\mathrm{Rpq}$ ) were carried out, using $0.1 \% \mathrm{CHCl}_{3}$ in a $2 \% \mathrm{HNO}_{3}$ blank (simulated matrix) and the standard solution contained the interfering blank (simulated matrix) together with a $10 \mu \mathrm{g} / \mathrm{L} \mathrm{Cr}$ spike. It was found that the best results could be obtained when $\mathrm{O}_{2}$ was used as the reaction gas but $\mathrm{CH}_{4}$ was not able to significantly reduce interferences at the mass of chromium. Operation at a flow rate of $0.85 \mathrm{ml} / \mathrm{min}$ 


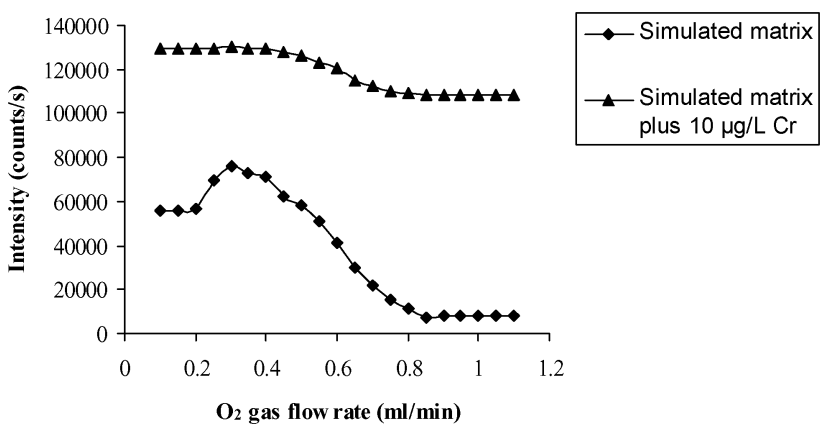

Fig. 1 Optimisation of $\mathrm{O}_{2}$ reaction gas flow for $\mathrm{Cr}(\mathrm{m} / \mathrm{z} 52)$ in $0.1 \%$ $\mathrm{CHCl}_{3}$ and $2 \% \mathrm{HNO}_{3}$ blank solution (simulated matrix), and $10 \mu \mathrm{g} / \mathrm{L} \mathrm{Cr}$ in simulated matrix.

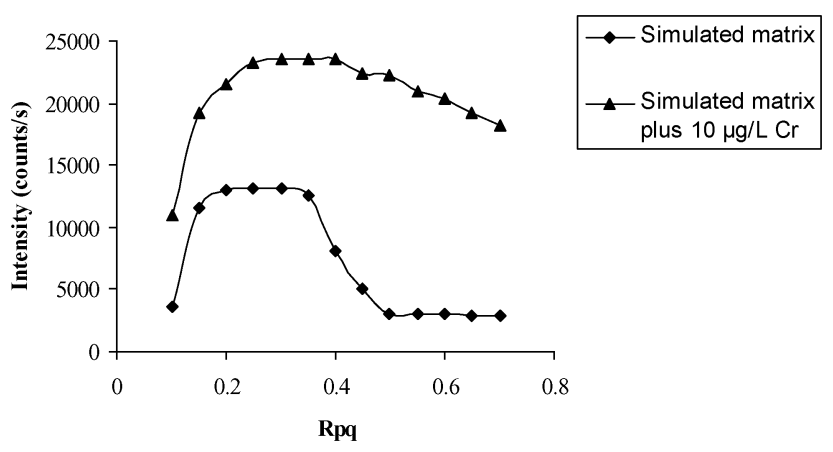

Fig. 2 DRC optimisation of Rpq value for $\mathrm{Cr}(\mathrm{m} / \mathrm{z} 52)$ in $0.1 \% \mathrm{CHCl}_{3}$ and $2 \% \mathrm{HNO}_{3}$ blank solution(simulated matrix), and $10 \mu \mathrm{g} / \mathrm{L} \mathrm{Cr}$ in simulated matrix.

and high-pass rejection parameter $\mathrm{q}(\mathrm{Rpq})=0.5$, provided a good estimated detection limit, as well as the best background equivalent concentrations (BEC) using $\mathrm{O}_{2}$. They were thus selected to be the subsequent operating conditions. The low-pass rejection parameter a (Rpa) did not affect ion signals when the value was $<0.1$. The Rpa value was thus set at 0 . Figs. 1 and 2 show the effect of the $\mathrm{O}_{2}$ flow rate and the Rpq value on the signal of $10 \mu \mathrm{g} / \mathrm{L} \mathrm{Cr}$ and the simulated matrix at mass 52 . As shown, the blank (or simulated matrix) signal, was suppressed significantly at an $\mathrm{O}_{2}$ flow rate of $0.85 \mathrm{ml} / \mathrm{min}$ and $\mathrm{Rpq}$ value of 0.5 . This demonstrates the effectiveness of the $\mathrm{O}_{2}$ reaction gas for the alleviation of spectroscopic interferences.

\section{Limits of detection (LOD)}

The LODs calculated as the concentration corresponding to three times the standard deviation of the average of 10 individually prepared blank solutions, were 0.091 and $0.085 \mu \mathrm{g} / \mathrm{L}$ for total $\mathrm{Cr}$ and $\mathrm{Cr}(\mathrm{VI})$, respectively. Lameiras et al. ${ }^{22}$ reported detection limits of 0.20 and 0.15 for total $\mathrm{Cr}$ and $\mathrm{Cr}(\mathrm{VI})$, respectively, in their studies of chromium speciation in UHT milk using ETAAS. These values are 2.20 and 1.76 times higher than the detection limits found for the method currently proposed. The low detection limits provided by the ICP-MS enables the determination of very low concentrations of chromium species in milk samples. Ho and Jiang ${ }^{37}$ reported a LOD of 3.0 for total $\mathrm{Cr}$, in their studies of milk powder using slurry sampling electrothermal vaporization ICP-MS with $\mathrm{NH}_{3}$ as reaction gas. This value is 33 times higher than the LOD obtained by our method for total $\mathrm{Cr}$.

\section{Validation of the method}

The accuracy and precision of the analytical method was carefully evaluated under optimum conditions in order to ensure that no change in the original oxidation state of chromium occurred during sample pretreatment. The recoveries of the added $\mathrm{Cr}(\mathrm{VI})$ were quantitative (Table 2), indicating lack of losses or contaminations during sample preparation. It also shows that the oxidation state of $\mathrm{Cr}(\mathrm{VI})$ was not altered during the extraction process.

The second recovery study was conducted to check the stability of $\mathrm{Cr}(\mathrm{VI})$ in milk. The recoveries for milk spiked with $10.0 \mu \mathrm{g} / \mathrm{L} \mathrm{Cr}(\mathrm{VI})$, after standing for 12, 24 and $48 \mathrm{~h}$ and application of the pre-concentration procedure, were found to be 97.9, 95.8 and $94.2 \%$, respectively.

The solid phase extraction method using Chromabond $\mathrm{NH}_{2}$ column and DRC-ICP-MS quantification, thus provided a complete and selective extraction and determination of $\mathrm{Cr}(\mathrm{VI})$ from milk supernatant, as observed during the validation of the method.

A reference whole milk powder (NIST SRM 8435, Gaithersburg, MD, USA) was analysed to test the accuracy of the total $\mathrm{Cr}$ quantification method. The total $\mathrm{Cr}$ concentration obtained by the analysis of the certified reference material by DRC-ICP-MS is shown in Table 2 along with the certified value. The observed value was generally in good agreement with the NIST certified value, indicating validity of our method for analysis of milk samples.

Table 2 Percentage recoveries of $\mathrm{Cr}(\mathrm{VI})$ in spiked milk samples and analysis of whole milk powder standard reference material (SRM 8435) for total $\mathrm{Cr}$

\begin{tabular}{cccccc}
\hline & & & & \multicolumn{2}{l}{$\begin{array}{l}\text { Total Cr method } \\
\text { validation }\end{array}$} \\
\cline { 1 - 2 } $\begin{array}{lllll}\text { Concentration } \\
\text { spiked }(\mu \mathrm{g} / \mathrm{L})\end{array}$ & $\begin{array}{l}\text { Concentration } \\
\text { obtained }(\mu \mathrm{g} / \mathrm{L})\end{array}$ & $\begin{array}{l}\% \text { Recovery } \\
\pm \mathrm{SD}\end{array}$ & $\begin{array}{l}\text { Observed } \\
(\mathrm{mg} / \mathrm{kg})\end{array}$ & $\begin{array}{l}\text { Certified } \\
(\mathrm{mg} / \mathrm{kg})\end{array}$ \\
\hline 2.50 & 2.48 & $99.2 \pm 3.4$ & & \\
5.00 & 4.82 & $96.4 \pm 4.8$ & $0.47 \pm 0.03$ & 0.5 \\
10.0 & 9.85 & $98.5 \pm 4.2$ & & \\
\hline
\end{tabular}

Table 3 Concentrations of $\mathrm{Cr}(\mathrm{VI})$ and total $\mathrm{Cr}$ in milk samples

\begin{tabular}{llll}
\hline & $\begin{array}{l}\mathrm{Cr}(\mathrm{VI}) \\
\text { concentration } \\
(\mu \mathrm{g} / \mathrm{L}) \pm \mathrm{SD}\end{array}$ & $\begin{array}{l}\text { Total Cr } \\
\text { concentration } \\
(\mathrm{ng} / \mathrm{g}) \pm \mathrm{SD}\end{array}$ & $\begin{array}{l}\text { Total Cr } \\
\text { concentration } \\
(\mu \mathrm{g} / \mathrm{L}) \pm \mathrm{SD}\end{array}$ \\
\hline Sample ID & $1.39 \pm 0.09$ & $415 \pm 13$ & $54.0 \pm 1.7$ \\
Brand 1 & $1.25 \pm 0.05$ & $327 \pm 12$ & $42.5 \pm 1.6$ \\
Brand 2 & $1.44 \pm 0.07$ & $338 \pm 10$ & $43.9 \pm 1.3$ \\
Brand 3 & $0.61 \pm 0.03$ & $255 \pm 7.2$ & $33.2 \pm 0.90$ \\
Brand 5 & $0.87 \pm 0.04$ & $275 \pm 8.2$ & $35.8 \pm 1.1$ \\
Brand 6 & $0.75 \pm 0.02$ & $439 \pm 14$ & $57.1 \pm 1.8$ \\
Brand 7 & $1.01 \pm 0.05$ & $306 \pm 7.7$ & $39.8 \pm 1.0$ \\
Brand 8 & $0.81 \pm 0.03$ & $397 \pm 11$ & $51.6 \pm 1.4$ \\
\hline
\end{tabular}




\section{Concentrations of $\mathrm{Cr}(\mathrm{VI})$ and total $\mathrm{Cr}$ in samples}

$\mathrm{Cr}(\mathrm{VI})$ and total $\mathrm{Cr}$ concentrations in milk samples were quantified by ICP-MS. The SD for $\mathrm{Cr}(\mathrm{VI})$ and total $\mathrm{Cr}$ concentrations for the eight commercial brands, (each sampled in triplicate) are given in Table 3.

The relative standard deviations (RSD) of milk samples for $\mathrm{Cr}(\mathrm{VI})$ and total $\mathrm{Cr}$ were found to be in the range of 2.67 to $6.47 \%$ and 2.54 to $3.67 \%$, respectively. These low RSD indicate the good precision of the methodology during practical analysis.

$\mathrm{Cr}(\mathrm{VI})$ is easily absorbed through the gastrointestinal tract and is a genotoxic species. For proper comparison of the total $\mathrm{Cr}$ level with $\mathrm{Cr}(\mathrm{VI})$, the total $\mathrm{Cr}$ level in all freeze-dried milk samples, given by ng/g dry mass, were converted to $\mu \mathrm{g} / \mathrm{L}$ (Table 3 ). Considering that the solid extract of raw milk is $130 \mathrm{~g} / \mathrm{L},{ }^{22}$ and after converting the results into $\mu \mathrm{g} / \mathrm{L}$, levels ranging from 33.2 to $57.1 \mu \mathrm{g} / \mathrm{L}$ were found for total $\mathrm{Cr}$. On the basis of these results, milk samples contained 1.31 to $3.28 \% \mathrm{Cr}(\mathrm{VI})$. This indicates the presence of $\mathrm{Cr}(\mathrm{VI})$ in relatively low concentrations with reference to the total $\mathrm{Cr}$. Consequently there is a low risk to consumers.

For total chromium, the values found for five brands $(2,3,4,5$ and 7) were within the same range with the results reported previously. ${ }^{17}$ The values for three brands (1,6 and 8) were slightly higher than reported in that paper. The higher concentrations of total $\mathrm{Cr}$ in these commercial brands could be influenced by environmental conditions such as proximity to mines, or the equipment processing the milk. Stainless steel is commonly used for manufacturing the equipment used in pasteurising, clarifying and processing milk as it is easily cleaned and considered relatively inert. It can, however, contain chromium.

The blank values are at the sub $\mu \mathrm{g} / \mathrm{L}$ level $(0.01$ to $0.03 \mu \mathrm{g} / \mathrm{L})$, despite carrying out the sample preparation in a normal laboratory environment and might be further reduced in a special, clean lab.

The method developed, enables selective determination of low concentrations of $\mathrm{Cr}(\mathrm{VI})$ in the presence of $\mathrm{Cr}$ (III) up to 75-fold higher. Real sample analysis results obtained from this study allowed a determination of $1.31 \% \mathrm{Cr}(\mathrm{VI})$ of total $\mathrm{Cr}$ in milk. The experiments also demonstrated that $\mathrm{Cr}(\mathrm{VI})$ and total $\mathrm{Cr}$ in milk samples can be determined by DRC-ICP-MS without significant spectroscopic interferences.

The Codex Alimentarius Commission does not currently have a MRL for chromium because it is both an essential element and a toxic residue. This method offers the possibility of benchmarking the MRL for $\mathrm{Cr}(\mathrm{VI})$, the toxic state of the element, by using the proposed method of speciation.

\section{Acknowledgements}

Tshwane University of Technology (TUT) and National Research Fund (NRF) are gratefully acknowledged for financial assistance.

\section{References}

1 L. Soko, E. Cukrowska and L. Chimuka, Anal. Chim. Acta, 2002, 474, 59-68.

2 Kirk-Othmer Encyclopedia of Chemical Technology, 4th edn., vol. 6, Wiley, New York, 1992, 228-311.

3 M. Tuzen and M. Soylak, J. Hazard. Mater., 2006, B129, 266-273.

4 D. E. Kimbrough, Y. Cohen, A. M. Winer, L. Creelman and C. Mabuni, Crit. Rev. Environ. Sci. Technol., 1999, $29,1$.

5 J. Kotas and Z. Stasicka, Environ. Pollut., 2000, 107, 263-283.

6 A. R. Anderson and A. S. Kozlosvky, Am. J. Clin. Nutr., 1985, 41, 1117.

7 E. J. Underwood, Trace Elements in Human and Animal Nutrition, Academic Press, New York, 4th edn, 1977, ch. 10, pp. 258-270.

8 P. O'Brien and G. Wang, Env. Geochem. Health, 1989, 11, 77.

9 M. K. Donais, R. Henry and T. Rettberg, Talanta, 1999, 49, 10451050.

10 E. Coni, S. Caroli, D. Ianni and A. Bocca, Food Chem., 1994, 50, $203-$ 210.

11 E. Coni, A. Bocca, D. Ianni and S. Caroli, Food Chem., 1995, 52, $123-$ 130.

12 E. Coni, A. Bocca, P. Coppolelli, S. Caroli, C. Cavallucci and M. T. Marinucci, Food Chem., 1996, 57, 253-260.

13 F. A. R. Martino, M. L. F. Sánchez and A. S. Medel, J. Anal. At. Spectrom., 2000, 15, 163-168.

14 F. A. R. Martino, M. L. F. Sánchez and A. Sanz-Medel, Anal. Chim. Acta, 2001, 442, 191-200.

15 C. S. Kira and F. D. Maio, J. AOAC Int., 2004, 87, 151-156.

16 R. Caggiano, S. Sabia, M. D'Emilio, M. Macchiato, A. Anastasio, M. Ragosta and S. Paino, Environ. Res., 2005, 99, 48-57.

17 A. Ataro, R. I. McCrindle, B. M. Botha, C. M. E. McCrindle and P. P. Ndibewu, Food Chem., 2008, 111, 243-248.

18 O. Abollino, M. Aceto, M. C. Bruzzoniti, E. Mentasti and C. Sarzanini, Anal. Chim. Acta, 1998, 375, 299-306.

19 P. Cava-Montesinos, A. de la Guardia, C. Teutsch, M. L. Cervera and M. de la Guardia, Anal. Chim. Acta, 2003, 493, 195-203.

20 P. Bermejo, E. Peña, R. Domínguez, A. Bermejo, J. M. Fraga and J. A. Cocho, Talanta, 2000, 50, 1211-1222.

21 P. Brätter, I. N. Blasco, V. E. N. de Brätter and A. Raab, Analyst, 1998, 123, 821-826.

22 J. Lameiras, M. E. Soares, M. L. Bastos and M. Ferreira, Analyst, 1998, 123, 2091-2095.

23 Y. Li, N. K. Pradhan, R. Foley and G. K. C. Low, Talanta, 2002, 57, $1143-1153$

24 P. G. Krishna, J. M. Gladis, U. Rambabu, T. P. Rao and G. R. K. Naidu, Talanta, 2004, 63, 541-546.

25 C. Sarzanini, J. Chromatogr. A, 1999, 850, 213-228.

26 I. Narin, A. Kars and M. Soylak, J. Hazard. Mater., 2008, 150, 453458.

27 H.-L. Ma and P. A. Tanner, Talanta, 2008, 77, 189-194.

28 F. Vanhaecke, H. Vanhoe and R. Dams, Talanta, 1992, 39, 737-742.

29 S. J. Hill, Inductively coupled plasma spectrometry and its applications, Blackwell Publishing Ltd, Oxford, $1^{\text {st }}$ edn., 2007, pp. 134-413.

30 V. Dufailly, L. Noël and Thierry Guérin, Anal. Chim. Acta, 2006, 565, 214-221.

31 Z.-L. Chen, M. Megharaj and R. Naidu, Talanta, 2007, 73, 948-952.

32 A. P. Vonderheide, J. Meija, K. Tepperman, A. Puga, A. R. Pinhas, J. C. States and J. A. Caruso, J. Chromatogr. A, 2004, 1024, 129-137.

33 S. D'Ilio, N. Violante, M. D. Gregorio, O. Senofonte and F. Petrucci, Anal. Chim. Acta, 2006, 579, 202-208.

34 C.-Y. Ho and S.-J. Jiang, Spectrochim, Acta, Part B, 2003, 58, 63-70.

35 S. D'Ilio, N. Violante, S. Caimi, M. D. Gregorio, F. Petrucci and O. Senofonte, Anal. Chim. Acta, 2006, 573-574, 432-438.

36 P.-C. Li and S.-J. Jiang, Anal. Chim. Acta, 2003, 495, 143-150.

37 C.-Y. Ho and S.-J. Jiang, J. Anal. At. Spectrom., 2002, 17, 688-692. 